\title{
O banco de dados do Prêmio Nobel como indicador da internacionalização da ciência brasileira entre 1901 e 1966
}

\author{
The Nobel Prize database as an indicator of the \\ internationalization of Brazilian science from 1901 to 1966
}

\section{José Eymard Homem Pittella}

Professor aposentado, Faculdade de Medicina, Universidade Federal de Minas Gerais.

Belo Horizonte - MG - Brasil

jehpittella@hotmail.com

Recebido em 18 out. 2016.

Aprovado em 5 set. 2017.
PITELLA, José Eymard Homem. O banco de dados do Prêmio Nobel como indicador da internacionalização da ciência brasileira entre 1901 e 1966. História, Ciências, Saúde - Manguinhos, Rio de Janeiro, v.25, n.2, abr.-jun. 2018, p.569-590.

\section{Resumo}

O trabalho explora o potencial de análise da participação de brasileiros indicados à mais prestigiada premiação mundial em ciência, o Nobel, bem como dos brasileiros convidados para indicar candidatos à premiação, com base no banco de dados do Prêmio Nobel, cobrindo o período 1901-1966. Dezoito brasileiros foram indicados ao Prêmio Nobel, dos quais nove ao da Paz, quatro ao de Literatura, quatro ao de Fisiologia ou Medicina e um ao de Física. São comentadas as indicações dos cientistas brasileiros à premiação de Física e de Fisiologia ou Medicina e as dos nomeadores brasileiros nestas duas últimas categorias. Discute-se o processo de avaliação em ciência com base no conhecimento obtido após análise dos dados referentes à premiação do Nobel.

Palavras-chave: Prêmio Nobel; banco de dados; história da física; história da medicina; ciência brasileira.

\section{Abstract}

Working with the Nobel Prize database, covering 1901-1966, the article examines the analytical potential of the participation of Brazilians both as nominees for the world's most prestigious award in science, the Nobel Prize, and also as invited nominators. Of the 18 Brazilians nominated for the Nobel, nine were in the category Peace, four in Literature, four in Physiology or Medicine, and one in Physics. The article comments on the nominations of Brazilian scientists in the categories of Physics and Physiology or Medicine, as well as on nominations by Brazilian nominators in these same two categories. It also discusses the process of science evaluation, based on the information attained through analysis of these data on the Nobel award.

Keywords: Nobel Prize; database; history of physics; history of medicine; Brazilian science. 
$\mathrm{D}$ entre as centenas de premiações prestigiosas que reconhecem o que é tido como excelência na pesquisa científica, destaca-se o Prêmio Nobel, a maior premiação mundial da ciência. O prêmio, instituído a partir de 1901, conforme desejo expresso em testamento pelo engenheiro e empresário sueco Alfred Nobel (1833-1896), inventor da dinamite, titular de 355 patentes e dono de vasta fortuna, é concedido às pessoas responsáveis por descoberta, invenção ou aperfeiçoamento considerados de benefício para a humanidade.

Desde o começo, a premiação atraiu grande interesse, tanto pela percepção que a sociedade da época tinha da importância da ciência e suas aplicações na vida das pessoas quanto pela novidade de se fazer uma grande doação para causas científicas e filantrópicas. Com o passar dos anos e com a crescente fama do Prêmio Nobel, ele tornou-se um símbolo da organização e excelência do ensino acadêmico, bem como de conquista e realização científicas reconhecidas mundialmente, impactando a vida dos laureados e suas instituições de origem e/ou afiliação. Este último aspecto pode ser observado nos sites oficiais das instituições às quais os laureados com o Nobel são afiliados, que publicam listas com o nome do laureado, a categoria e o ano da premiação.

Apenas para citar um exemplo, no site oficial da Universidade de Cambridge, em Cambridge, Reino Unido, consta que 96 de seus afiliados foram laureados com o Prêmio Nobel, em todas as categorias, entre 1904 e 2016: 32 em Física, 26 em Fisiologia ou Medicina, 22 em Química, 11 em Economia, três em Literatura e dois com o Nobel da Paz. Segundo Crawford (1992, p.7), o Nobel representa o ápice da hierarquia de concessões honoríficas.

O processo da premiação com o Nobel segue regras bem definidas. O Comitê Nobel de Física e de Fisiologia ou Medicina envia convites confidenciais para pessoas qualificadas para indicar candidatos ao prêmio (nomeadores). Para a indicação de candidatos na categoria de Física, são qualificados membros suecos e estrangeiros da classe de física da Academia Real Sueca de Ciências, membros do Comitê Nobel de Física, laureados com o Nobel de Física e Química, professores titulares de física em universidades e institutos de tecnologia de Suécia, Dinamarca, Finlândia, Islândia e Noruega, além do Instituto Karolinska (sede da Faculdade de Medicina), em Estocolmo, e professores titulares de física de pelo menos seis universidades selecionadas pela Academia Real Sueca de Ciências, entre centenas de universidades espalhadas por diferentes países, visando assegurar uma distribuição representativa, além de outros cientistas que a Academia Real considerar oportuno convidar. Os candidatos indicados são selecionados preliminarmente pelo Comitê Nobel de Física, o qual é constituído de cinco titulares, além de membros adjuntos. Os candidatos selecionados preliminarmente são então submetidos à avaliação por especialistas indicados pelo Comitê Nobel de Física. Com base nessa avaliação, o Comitê Nobel elabora uma lista de candidatos para a avaliação final pelos físicos da Academia Real Sueca de Ciências, os quais selecionam o(s) premiado(s) pelo Nobel em votação majoritária. Nessa avaliação final, podem surgir modificações da lista de candidatos ou encaminhamento de uma proposta diferente para a premiação (Nomination and Selection of Physics..., s.d.).

Para a categoria de Fisiologia ou Medicina, são qualificados para indicar candidatos ao Prêmio Nobel membros da Assembleia Nobel do Instituto Karolinska, membros suecos e estrangeiros da classe de biologia e medicina da Academia Real Sueca de Ciências, laureados com o Nobel de Fisiologia ou Medicina e Química, membros do Comitê Nobel de Fisiologia 
ou Medicina, professores titulares das faculdades de medicina de Suécia, Dinamarca, Finlândia, Islândia e Noruega, e professores titulares de pelo menos seis faculdades de medicina selecionadas pela Assembleia Nobel, entre centenas de universidades espalhadas por diferentes países, visando assegurar uma distribuição representativa, além de outros cientistas que a Academia Real considerar oportuno convidar. Os candidatos indicados são então submetidos à avaliação por especialistas de reputação internacional indicados pelo Comitê Nobel de Fisiologia ou Medicina, o qual é formado por cinco membros e o secretário do Comitê Nobel e o da Assembleia Nobel. Com base nessa avaliação, o Comitê Nobel elabora uma lista de candidatos para avaliação final pela Assembleia Nobel, constituída por cinquenta membros, sendo que a escolha do(s) premiado(s) é feita por votação majoritária (Nomination and Selection of Medicine..., s.d.). Nas duas categorias (Física e Fisiologia ou Medicina) a decisão é final e sem apelação. As informações sobre quem são os nomeadores e indicados permanecem secretas durante cinquenta anos. Não pode haver autoindicação nem indicação de pessoas já falecidas. Antes de 1974, pessoas falecidas poderiam receber a premiação postumamente, caso tivessem sido indicadas antes do dia primeiro de fevereiro do mesmo ano da premiação e falecidas antes da data do recebimento da premiação, em dezembro. A partir daquele ano, o prêmio passou a só ser concedido a uma pessoa falecida caso tivesse sido laureada (usualmente no mês de outubro), mas tenha falecido antes de receber a premiação, em 10 de dezembro do mesmo ano (Lemmel, 2011).

A abertura, em 1974, dos arquivos do Prêmio Nobel da Academia Real Sueca de Ciências e a divulgação pela internet, a partir de 1995, do banco de dados de nomeadores e indicados (Nomination Archive, s.d.), permitiu acesso aos documentos datados de pelo menos cinquenta anos e possibilitou a pesquisa e a análise de diferentes aspectos da premiação, incluindo identificação e distribuição dos laureados, indicados e nomeadores de acordo com suas nacionalidade e afiliação.

Os arquivos do Prêmio Nobel tornaram-se fontes imprescindíveis aos interessados em investigar os diversos fatores envolvidos na nomeação e condecoração, tanto dos laureados como também daqueles que foram indicados mas não premiados. O estudo desses documentos trouxe informações sobre o que era considerada uma realização científica de vulto na primeira metade do século XX, quem eram os cientistas importantes, quais eram as relações entre eles e como funcionaram as engrenagens de patronato científico. Além disso, mostrou que as decisões dos membros do Comitê Nobel eram guiadas tanto por seus próprios interesses em ciência quanto por deliberações anteriores à premiação.

A historiografia que se originou da análise dessa documentação colocou-se criticamente em relação à visão do Nobel como sistema neutro de premiação e recompensa, que seria conferido com base no mérito e relevância intrínsecos do pesquisador e de sua contribuição à ciência, fundado no suposto ethos universalista dessa prática intelectual (Crawford, 1984, 1992, 1998, 2002; Crawford, Sime, Walker, 1997; Dardo, 2004; Friedman, 2001; Hargittai, 2002; Zuckerman, 1977).

O trabalho da historiadora das ciências Elizabeth Crawford publicado em 1984 resultou de cinco anos de pesquisa nos arquivos. Desde então, ela interessou-se em mostrar, a partir, basicamente, das áreas de física e química, como a análise das indicações e premiações evidencia as contingências históricas que marcaram a internacionalização das ciências. 
Visto como símbolo de uma ciência internacionalizada, o Nobel, segundo Crawford (1992), apresentou vieses nacionalistas, principalmente no período da Primeira Guerra Mundial, quando as comunidades dos países beligerantes estenderam à arena intelectual as rivalidades e os ressentimentos das trincheiras. Sobretudo franceses, alemães e ingleses, mostra-nos Crawford, favoreceram ou boicotaram compatriotas e oponentes nas indicações. Dessa forma, a autora argumenta como o nacionalismo e o internacionalismo nas ciências devem ser vistos como valores justapostos que estão em constante interação.

Fartamente baseado nas fontes históricas dos arquivos do Nobel, bem como em documentos de arquivos privados de membros do comitê, Friedman (2001) apresenta imagem bastante iconoclasta da premiação, ao explorar as controvérsias, os favorecimentos, as intrigas e motivações mesquinhas que acompanharam as nomeações e condecorações. Não estiveram ausentes desse processo, mostra o historiador, elementos como racismo e sexismo, este último aspecto também explorado por Hargittai (2002). Para Friedman (2001, p.IX), o Prêmio Nobel atuou como recurso estratégico dos pesquisadores para explorar "suas próprias agendas científicas, culturais e pessoais". Analisando detalhadamente vários casos controversos e a constante falta de consenso do comitê, Friedman atesta que o Prêmio Nobel representou mais um instrumento de política de ciência do que de aferição de mérito.

Refletindo as profundas assimetrias que o Prêmio Nobel legitima em termos do que se considera uma contribuição de relevo e do acesso diferenciado a recursos materiais e simbólicos, essa historiografia favorece os países europeus e da América do Norte. Praticamente se ignora a participação do chamado "Sul Global" no sistema de recompensas do Nobel. Embora o Comitê Nobel de Fisiologia ou Medicina tenha sido pioneiro, antes da Segunda Guerra Mundial, em solicitar recomendações de indicados ao prêmio nessa categoria, de cientistas procedentes de países como Japão, China, Índia, Turquia e Egito (Bartholomew, 2005, p.627), houve indicação de apenas 13 cientistas japoneses, dois chineses, um indiano, um turco (que não foram laureados) e nenhum egípcio, naquele período (Nomination Database. Countries..., s.d.). No que concerne ao Brasil, alguns trabalhos divulgaram listas com nomes de brasileiros indicados ao Prêmio Nobel em algumas categorias, e foram publicados artigos contendo análises da indicação de Carlos Chagas (Coutinho, Freire Jr., Dias, 1999; Gurgel, Magdalena, Prioli, 2009; Lewinsohn, 2003) e de César Lattes (Nascimento, 2015). É necessário ampliar a análise para incluir os demais cientistas brasileiros indicados à premiação, as contribuições que eles trouxeram e a inserção dos indicados no panorama da comunidade científica da época, incluindo uma comparação com as contribuições trazidas pelos laureados e os com maior número de indicações no mesmo ano ou época da indicação dos brasileiros. Além disso, cabe explorar a participação de cientistas brasileiros na indicação de candidatos à premiação pelo Nobel, não havendo estudos sobre esse tópico, exceto no caso de Carlos Chagas (Coutinho, Freire Jr., Dias, 1999; Pittella, 2009).

Esta nota de pesquisa pretende atender parcialmente a esses objetivos, enumerando, a partir de consulta à base de dados presente na web (Nomination Archive, s.d.), os brasileiros indicados às diversas categorias do Prêmio Nobel, o ano da indicação e o número de indicações, e, no caso da premiação nas categorias de física e fisiologia ou medicina, comentar brevemente as contribuições desses pesquisadores e suas relações com cientistas e 
instituições científicas de outros países. Além disso, descrevem-se os brasileiros convidados para participar da indicação de candidatos à premiação na categoria de física e de fisiologia ou medicina, com dados sobre a identificação de cada um, instituição de origem, ano do convite e nome e contribuição do indicado pelo brasileiro. Será também comparada a participação de cientistas brasileiros indicados à premiação e nomeadores nas duas categorias da premiação em análise, e o que pode revelar essa comparação.

Esses dados ajudam a mensurar o nível de integração dos cientistas brasileiros com as redes científicas hegemônicas, ou seja, representam, em certo nível, o grau de internacionalização da física e medicina brasileiras no período sob análise (1901-1966). Dessa forma, ajudam a compreender o potencial e os limites dessas áreas na arena internacional a partir do reconhecimento que seus representantes e suas contribuições obtiveram pelos seus pares. Com inspiração na literatura mencionada, é importante levar em conta que a internacionalização referendada pelo Nobel é um processo marcado por contingências sociais, culturais e históricas. Menos do que mero termômetro do nível de adiantamento das comunidades científicas, o número de laureados e de participantes na nomeação é indicativo de um padrão cumulativo de reconhecimento nas ciências, por meio do qual redes hegemônicas se retroalimentam, por arbitrar os parâmetros do que se considera uma contribuição científica relevante e possuir acesso privilegiado aos recursos para alcançá-las e validá-las.

As informações obtidas são um convite sedutor para o aprofundamento desses aspectos a partir da pesquisa nas fontes documentais sob a guarda do Instituto Karolinska.

\section{Brasileiros indicados para o Prêmio Nobel nas diversas categorias da premiação}

A Tabela 1 mostra a relação dos brasileiros indicados para o Prêmio Nobel nas diversas categorias da premiação, incluindo o ano e o número de indicações, com base no banco de dados da Fundação Nobel (Nomination Database. Countries..., s.d.). Para as categorias de fisiologia ou medicina, física, literatura e paz, as indicações referem-se aos períodos 1901-1953, 1901-1966, 1901-1966 e 1901-1967, respectivamente. Não houve indicação de brasileiros para a categoria da premiação em química.

O maior número de brasileiros indicados e de indicações foi ao Prêmio da Paz, com nove pessoas indicadas e uma instituição, totalizando 81 indicações. Afrânio de Melo Franco, político e diplomata, foi quem recebeu o maior número de indicações, 46 no total, tendo recebido 43 indicações em 1935, duas indicações em 1937 e uma indicação em 1938. Na categoria de literatura, quatro escritores foram indicados, todos tendo sido indicados apenas uma vez, exceto Henrique M. Coelho Neto, que foi indicado três vezes em 1933 (Tabela 1).

$\mathrm{Na}$ categoria de física, apenas um cientista brasileiro foi indicado, César Lattes. O físico brasileiro graduou-se no curso de física na Universidade de São Paulo, em 1943, com apenas 19 anos, sob a orientação do físico ítalo-russo Gleb Vassielievitch Wataghin (1899-1986). Na década de 1930, a pesquisa na área de física no Brasil havia começado a mudar significativamente, com a contratação de Wathagin e do físico italiano Giuseppe Paolo Stanislao Occhialini (1907-1993), em 1934 e 1937, respectivamente, para trabalhar no Departamento de Física da recém-criada Faculdade de Filosofia, Ciências e Letras, núcleo 
Tabela 1: Brasileiros indicados para o Prêmio Nobel nas diversas categorias da premiação, incluindo o ano e número de indicações, no período 1901-1967 [1], com base no banco de dados da Fundação Nobel [2]

\begin{tabular}{|c|c|c|c|}
\hline Categoria (período) & Ano & Indicado & $\begin{array}{l}\text { Número de } \\
\text { indicações }\end{array}$ \\
\hline Física (1901-1966) & $\begin{array}{l}1949 \\
1951 \\
1952 \\
1953 \\
1954\end{array}$ & $\begin{array}{l}\text { César Lattes (1924-2005) } \\
\text { César Lattes } \\
\text { César Lattes } \\
\text { César Lattes } \\
\text { César Lattes }\end{array}$ & $\begin{array}{l}2 \\
1 \\
2 \\
1 \\
1\end{array}$ \\
\hline $\begin{array}{l}\text { Fisiologia ou Medicina } \\
(1901-1953)\end{array}$ & $\begin{array}{l}1913 \\
1921 \\
1934 \\
1938 \\
1946 \\
1951 \\
1953\end{array}$ & $\begin{array}{l}\text { Carlos Chagas (1879-1934) } \\
\text { Carlos Chagas } \\
\text { Antônio Cardoso Fontes (1879-1943) } \\
\text { Adolfo Lutz (1855-1940) } \\
\text { Manoel Dias de Abreu (1891-1962) } \\
\text { Manoel Dias de Abreu } \\
\text { Manoel Dias de Abreu }\end{array}$ & $\begin{array}{l}1 \\
1 \\
1 \\
1 \\
4 \\
1 \\
1\end{array}$ \\
\hline Literatura (1901-1966) & $\begin{array}{l}1933 \\
1939 \\
1941 \\
1965\end{array}$ & $\begin{array}{l}\text { Henrique M. Coelho Neto (1864-1934) } \\
\text { Flávio de Carvalho (1899-1973) } \\
\text { Manoel Wanderley } \\
\text { Alceu Amoroso Lima (1893-1983) }\end{array}$ & $\begin{array}{l}3 \\
1 \\
1 \\
1\end{array}$ \\
\hline Paz (1901-1967) & $\begin{array}{c}1911 \\
1916 \\
1924[3] \\
1935 \\
1937 \\
1938 \\
1948 \\
1952 \\
1953\end{array}$ & $\begin{array}{l}\text { José Maria da Silva Paranhos Júnior, Barão do Rio Branco } \\
\text { (1845-1912) } \\
\text { Érico Marinho da Gama Coelho (1849-1922) } \\
\text { Raimundo Teixeira Mendes (1855-1927) } \\
\text { Afrânio de Melo Franco (1870-1943) } \\
\text { Afrânio de Melo Franco } \\
\text { Afrânio de Melo Franco } \\
\text { Oswaldo Euclides de Sousa Aranha (1892-1960) } \\
\text { Henrique P. Vasconcellos } \\
\text { Cândido Mariano da Silva Rondon (1865-1958) } \\
\text { Josué de Castro (1908-1973) } \\
\text { Raul Fernandes (1877-1967) } \\
\text { Raul Fernandes } \\
\text { Cândido Mariano da Silva Rondon } \\
\text { Josué de Castro } \\
\text { Josué de Castro } \\
\text { Josué de Castro }\end{array}$ & $\begin{array}{c}2 \\
1 \\
1 \\
43 \\
2 \\
1 \\
9 \\
1 \\
4 \\
3 \\
2 \\
1 \\
6 \\
1 \\
1 \\
2\end{array}$ \\
\hline
\end{tabular}

Fonte: Fundação Nobel. Disponível em: http://www.nobelprize.org/nomination/archive/list.php. Acesso em: 17 jun. 2017.

[1] Para as categorias de Fisiologia ou Medicina, Física e Literatura, as indicações referem-se ao período 1901-1953, 1901-1966 e 19011966, respectivamente.

[2] Cientistas nascidos em outros países, mas que trabalharam em instituições brasileiras e obtiveram a nacionalidade brasileira, receberam também indicações para o Prêmio Nobel de Física [David Bohm (1917-1992), uma indicação em 1958] e de Química [Fritz Feigl (1891-1971) uma indicação em 1955, 1957 e 1962 e duas indicações em 1963 e 1966].

[3] O Instituto Histórico-Geográfico Brasileiro recebeu uma indicação em 1924.

da futura Universidade de São Paulo (IF..., 4 set. 2014; Vieira, Videira, 2014). A vinda para o Brasil desses dois cientistas inaugurou uma nova concepção do ensino da física e abriu duas correntes de pesquisa, uma voltada para a física teórica e outra voltada para a física experimental. Occhialini, que havia sido também professor de Lattes, morou no Brasil de 1937 a 1944, mudando-se naquele mesmo ano para a Inglaterra a fim de trabalhar no H.H. Wills Physical Laboratory, da University of Bristol, dirigido por Cecil Powell (Gariboldi, Tucci, 2006, p.XVII-XXIV). A pedido do próprio Lattes, Occhialini conseguiu apoio para que o jovem físico brasileiro pudesse trabalhar no laboratório de Powell, em 1946, onde 
iniciou a pesquisa que o levaria à descoberta do méson pi (Vieira, Videira, 2014). Dois anos mais tarde, Lattes e o físico Eugene Gardner (1917-1950) conseguiram também detectar artificialmente o méson pi no acelerador de partículas na Universidade da Califórnia, em Berkeley.

Assim como Lattes, outros jovens físicos brasileiros que ganharam projeção na área foram formados direta ou indiretamente por Wataghin e Occhialini na Universidade de São Paulo, como Oscar Sala (1922-2010), Mário Schenberg (1914-1990), José Leite Lopes (1918-2006), Marcelo Damy de Souza Santos (1914-2009), Jayme Tiomno (1920-2011) e Roberto Salmeron (1922-).

Lattes foi indicado cinco vezes ao Prêmio Nobel entre 1949-1954, tendo recebido duas indicações duas vezes (1949 e 1952) e uma indicação três vezes (1951, 1953 e 1954). As indicações de César Lattes foram todas feitas por cientistas de outros países: em 1949, por Walter S. Hill Rodriguez (Montevidéu, Uruguai) e James H. Bartlett (Princeton University, EUA); em 1951, por Gleb Vassielievitch Wataghin (Turim, Itália); em 1952, por Leopold Ruzick (Zurique, Suíça) e Marcel Schein (Chicago, EUA); em 1953 e 1954, novamente por Leopold Ruzick; este foi laureado com o Prêmio Nobel de Química em 1939. Todos os nomeadores físicos (Hill Rodriguez, Bartlett, Wataghin e Schein) tiveram contato com Lattes nos anos anteriores à sua indicação à premiação; Wataghin havia sido inclusive seu professor e orientador, conforme já mencionado, tendo retornado para a Itália em 1949. Contudo, não deixa de ser uma surpresa o fato de que Ruzick o tenha indicado três vezes (Nascimento, 2015).

Em 1949, quando César Lattes foi indicado duas vezes, Hideki Yukawa (1907-1981), com dez indicações, foi quem recebeu a premiação pela sua predição da existência de mésons, em 1935, com base no trabalho teórico sobre forças nucleares. A denominação "méson" foi sugerida para indicar uma partícula com massa intermediária entre a do próton e a do elétron. Em 1952, quando César Lattes recebeu novamente duas indicações, o suíço Felix Bloch (1905-1983) e o estadunidense Edward Mills Purcell (1912-1997), com sete e cinco indicações, respectivamente, foram os que receberam a premiação pelo desenvolvimento de novos métodos para medições de precisão magnética nuclear e descobertas em relação ao campo magnético dos núcleos atômicos. E, em 1950, o britânico Cecil Frank Powell (1903-1969), com 14 indicações (Powell já havia recebido oito indicações em 1949), recebeu a premiação pelo desenvolvimento do método fotográfico de estudo dos processos nucleares e descobertas relativas aos mésons realizadas com esse método, confirmando as previsões sobre a existência das partículas mediadoras da força forte ligando prótons e nêutrons no núcleo, propostas por Hideki Yukawa.

No entanto, o desenvolvimento do método fotográfico para o estudo e a descoberta da nova partícula, em 1947, teve êxito graças à participação fundamental de César Lattes (Nascimento, 2015; Novello, 2012; Vieira, Videira, 2014). A contribuição do cientista brasileiro se deu em dois aspectos: (1) ele aperfeiçoou o método da emulsão fotográfica destinada à fixação e observação da trajetória individual de partículas produzidas pela radiação cósmica em altitudes elevadas, adicionando boro à emulsão fotográfica e, com isso, permitindo exposições mais prolongadas e imagens mais estáveis antes das revelações das emulsões; (2) Lattes (24 maio 1947, p.694-697) foi também o principal pesquisador 
e primeiro autor do histórico artigo publicado na revista Nature em 1947 descrevendo o méson pi, posteriormente denominado "píon".

Contudo, Powell foi o único agraciado com o Prêmio Nobel de Física em 1950, o que é considerado uma grande injustiça com o pesquisador brasileiro, tendo em vista a sua contribuição fundamental para a descoberta do méson pi e o fato de que a premiação do Nobel pode ser concedida a até três cientistas para cada categoria, anualmente. Admite-se que o Comitê Nobel costuma premiar somente o líder do grupo de pesquisa; no caso, Cecil Powell. Além disso, Lattes não recebeu nenhuma indicação naquele ano, ao contrário de um dos outros coautores do artigo publicado na Nature, Occhialini, que recebeu três indicações em 1950. Além das três indicações para o Prêmio Nobel de Física em 1950, Occhialini recebeu outras 29 indicações no período de 1949 a 1965, três delas feitas por Cecil Powell. E, em 1949, Powell e Occhialini foram indicados juntos três vezes, enquanto, no mesmo ano, Powell, Occhialini e Lattes foram indicados juntos apenas uma vez. Ou seja, dos três principais pesquisadores da descoberta e do aperfeiçoamento do novo método fotográfico para o estudo de processos nucleares e da descoberta dos mésons, Lattes foi o menos reconhecido pela comunidade científica internacional de físicos qualificados para indicar candidatos ao Prêmio Nobel, até pelo próprio chefe do laboratório onde trabalhou, talvez por ser ainda muito jovem e proveniente de um país sul-americano, com pouca tradição científica na área de física.

Para finalizar este tópico, é necessário mencionar que no período de 1901 a 1966 o único cientista brasileiro convidado para nomeador na categoria de física para a premiação do Nobel foi o médico Carlos Chagas Filho (1910-2000), do Instituto de Biofísica da Universidade do Brasil. Ele indicou, em 1947, o físico estadunidense Donald William Kerst (1911-1993), responsável pelo desenvolvimento do acelerador de partículas bétatron. Quando indicou Kerst, com certeza Carlos Chagas Filho não havia ainda tomado conhecimento da descoberta do méson pi publicada em maio daquele ano, pois as indicações à premiação são submetidas ao Comitê Nobel até 31 de janeiro do ano da premiação. Na época de sua indicação como nomeador, Carlos Chagas Filho, embora ainda jovem, já era reconhecido por seu trabalho em física biológica, tendo feito especialização nessa área com os cientistas René Wurmser e Alfred Fessard, em Paris, e Archibald Vivian Hill, em Londres, em 1937 e 1938, além de ter buscado cooperação com renomados cientistas de outros países nos primeiros anos da década de 1940 (Almeida, 2012). A indicação de Carlos Chagas Filho para nomeador deve-se, certamente, tanto ao seu trabalho na física biológica quanto à sua rede de relações científicas internacionais. No período da premiação do Nobel ora examinado, é também o único exemplo de pai e filho brasileiros terem sido indicados ao prêmio e como nomeador, respectivamente.

Entre 1901 e 1953, quatro brasileiros foram indicados ao Prêmio Nobel na categoria de fisiologia ou medicina: Carlos Chagas, Antônio Cardoso Fontes, Adolfo Lutz e Manoel de Abreu (Tabela 1). É sintomático que, dos quatro, três tenham sido afiliados ao Instituto Oswaldo Cruz nas primeiras décadas do século XX, o que pode ser correlacionado à institucionalização da medicina tropical no período, bem como às estratégias bem-sucedidas de internacionalização perseguidas por Oswaldo Cruz desde a criação da instituição, em 1900 (Benchimol, 2001, p.61 e 73; Benchimol, Sá, 2005, p.190-208; Kropf, Sá, 2009; Silva, 2013). 
Carlos Chagas foi indicado ao Prêmio Nobel de Medicina ou Fisiologia em 1913 e 1921, recebendo uma indicação nos dois anos (Tabela 1), ambas por nomeadores brasileiros (Tabela 2), pela descrição da entidade nosológica batizada com seu nome. Chagas não foi contemplado com o Nobel. Em publicação anterior, foram comentadas as possíveis razões para a não premiação do Nobel para o genial cientista (Pittella, 2009, p.71). O não reconhecimento das descobertas de Carlos Chagas mostrou

que na prática a avaliação em ciência reflete principalmente as ligações que os membros da comunidade científica internacional têm entre si, o que é considerado realização científica e o grau de hierarquia existente nas comissões avaliadoras. As ligações dos membros do Instituto Karolinska e do Comitê Nobel com a comunidade científica internacional, centrada quase que exclusivamente em cientistas europeus e norteamericanos, influenciavam nas escolhas dos nomeadores, indicados e premiados, e sobre o que era considerada realização científica na época (Pittella, 2009, p.71).

Não procede a teoria conspiratória

de que a oposição enfrentada por Carlos Chagas por parte de alguns colegas em Manguinhos e na Academia Nacional de Medicina, que negavam a existência da doença ou tentavam reduzir sua importância, tenha sido um dos motivos para ele não ter recebido a premiação de 1921. Não há também documentos que comprovem a especulação de que o Comitê Nobel tenha se dirigido a instituições brasileiras e que essas tenham desaconselhado a premiação. O episódio da oposição a Carlos Chagas é profundamente lamentável, mas não deve ter influenciado a decisão quanto à premiação daquele ano (Pittella, 2009, p.71).

Chagas recebeu diversos prêmios e homenagens de instituições europeias e dos EUA, destacando-se entre outros o Prêmio Schaudinn, pelo melhor trabalho em protozoologia, concedido pelo Institut für Schiffs- und Tropenkrankheiten, de Hamburgo, em 1912. Dos seis cientistas que concorreram com Chagas ao Prêmio Schaudinn, três já eram ganhadores do Prêmio Nobel em Fisiologia ou Medicina e, um deles, um futuro laureado. É interessante notar que a comissão julgadora era composta de 25 cientistas, entre os quais, quatro dos concorrentes de Chagas e Oswaldo Cruz (Coutinho, Dias, 1999).

Antônio Cardoso Fontes recebeu, em 1934, uma indicação para o Prêmio Nobel de Fisiologia ou Medicina (Tabela 1), pelo trabalho sobre o ultravírus do bacilo da tuberculose, por um nomeador do Institut Pasteur, de Paris (Tabela 2). Embora negada por outros autores, Fontes admitia a existência de formas filtráveis do bacilo da tuberculose (Mycobacterium tuberculosis), que não se coravam pelo método de Ziehl-Nielsen, capazes de passar por filtros de cerâmica Berkefeld, modelo Nordmeyer, utilizados para impedir a passagem de bactérias na água utilizada para consumo da população (Fontes, 1910). Uma possibilidade de explicar os achados de Fontes foi a demonstração, em décadas posteriores, da existência de variantes do bacilo deficientes de parede celular, visualizadas como formas granulares não álcool-acidorresistentes, metabolicamente inativas, que permanecem latentes na presença de mecanismos de defesa do hospedeiro. Essas variantes somente reverteriam às formas álcool-acidorresistentes, coradas pelo método de Ziehl-Nielsen, nos pacientes imunocomprometidos, nos quais seriam então capazes de produzir doença (Chandrasekhar, Ratnam, 1992). Fontes participou de diversos congressos científicos 
Tabela 2: Relação dos cientistas brasileiros convidados para indicar candidatos ao Prêmio Nobel de Fisiologia ou Medicina, bem como dos três cientistas de outras nacionalidades que indicaram candidatos brasileiros ao Prêmio Nobel na mesma categoria, instituição de origem do convidado no ano do convite, ano da indicação e nome do indicado com sua respectiva contribuição, com base no banco de dados da Fundação Nobel, disponível para o período 1901-1953

\begin{tabular}{|c|c|c|c|c|}
\hline Ano & Nomeador & Instituição & Indicado & Contribuição \\
\hline 1912 & $\begin{array}{l}\text { Brant Paes Leme } \\
(1863-1943)\end{array}$ & Fac. Medicina RJ [3] & $\begin{array}{l}\text { Carlos Finlay } \\
(1833-1915)\end{array}$ & $\begin{array}{l}\text { Trabalho sobre a transmissão } \\
\text { da febre amarela }\end{array}$ \\
\hline 1913 & $\begin{array}{l}\text { Manuel Augusto Pirajá } \\
\text { da Silva (1873-1961) }\end{array}$ & U. Bahia [4] & $\begin{array}{l}\text { Carlos Chagas } \\
(1879-1934)\end{array}$ & $\begin{array}{l}\text { Descoberta de uma nova } \\
\text { doença pelo tripanossoma }\end{array}$ \\
\hline $1921[1]$ & $\begin{array}{l}\text { Hilário Soares de } \\
\text { Gouvêa (1843-1923) }\end{array}$ & U. Rio de Janeiro [5] & Carlos Chagas & $\begin{array}{l}\text { Pesquisa sobre malária e a } \\
\text { descoberta do Trypanosoma } \\
\text { cruzi }\end{array}$ \\
\hline $1921[1]$ & C.S. de Magalhães [2] & U. Rio de janeiro & $\begin{array}{l}\text { Patrick Manson } \\
(1844-1922)\end{array}$ & $\begin{array}{l}\text { Trabalho no campo da } \\
\text { medicina tropical }\end{array}$ \\
\hline 1924 & $\begin{array}{l}\text { João Aguiar Pupo } \\
(1890-1980)\end{array}$ & $\begin{array}{l}\text { Fac. Medicina de São } \\
\text { Paulo [6] }\end{array}$ & $\begin{array}{l}\text { Constantin Levaditi } \\
(1874-1953)\end{array}$ & $\begin{array}{l}\text { Trabalho sobre sífilis } \\
\text { experimental }\end{array}$ \\
\hline 1925 [1] & $\begin{array}{l}\text { Henrique da Rocha } \\
\text { Lima (1879-1956) }\end{array}$ & $\begin{array}{l}\text { Institut für Schiffs- und } \\
\text { Tropenkrankheiten, } \\
\text { Hamburgo, Alemanha }\end{array}$ & $\begin{array}{l}\text { Hideo Noguchi } \\
(1876-1928)\end{array}$ & $\begin{array}{l}\text { Trabalho sobre febre amarela } \\
\text { e sobre espiroqueta da sífilis }\end{array}$ \\
\hline 1934 & $\begin{array}{l}\text { Michel Weinberg } \\
(1868-1940)\end{array}$ & $\begin{array}{l}\text { Institut Pasteur, Paris, } \\
\text { França }\end{array}$ & $\begin{array}{l}\text { Antônio Cardoso } \\
\text { Fontes (1879-1943) }\end{array}$ & $\begin{array}{l}\text { Trabalho sobre o ultravírus do } \\
\text { bacilo da tuberculose }\end{array}$ \\
\hline 1938 & $\begin{array}{l}\text { Octávio Coelho de } \\
\text { Magalhães } \\
(1890-1972)\end{array}$ & U. Minas Gerais [7] & $\begin{array}{l}\text { Adolfo Lutz } \\
(1855-1940)\end{array}$ & $\begin{array}{l}\text { Trabalho sobre doenças } \\
\text { tropicais (lepra, esporotricose, } \\
\text { febre amarela, malária) }\end{array}$ \\
\hline $1941[1]$ & $\begin{array}{l}\text { Luciano Gualberto } \\
(1883-1959)\end{array}$ & U. São Paulo & $\begin{array}{l}\text { Walter B. Cannon } \\
(1871-1945)\end{array}$ & $\begin{array}{l}\text { Trabalho sobre a secreção de } \\
\text { adrenalina e sua relação com } \\
\text { o sistema nervoso simpático }\end{array}$ \\
\hline $1941[1]$ & $\begin{array}{l}\text { Renato Locchi } \\
(1896-1978)\end{array}$ & U. São Paulo & Walter B. Cannon & $"$ \\
\hline $1941[1]$ & $\begin{array}{l}\text { Antônio de Almeida } \\
\text { Prado (1889-1965) }\end{array}$ & U. São Paulo & Walter B. Cannon & $"$ \\
\hline $1941[1]$ & $\begin{array}{l}\text { Flaminio Favero } \\
(1895-1982)\end{array}$ & U. São Paulo & Walter B. Cannon & $"$ \\
\hline $1941[1]$ & $\begin{array}{l}\text { Franklin Augusto de } \\
\text { Moura Campos } \\
(1896-1962)\end{array}$ & U. São Paulo & Walter B. Cannon & $"$ \\
\hline $1941[1]$ & $\begin{array}{l}\text { Ludgero da Cunha } \\
\text { Motta (1888-1967) }\end{array}$ & U. São Paulo & $\begin{array}{l}\text { Harry Goldblatt } \\
(1891-1977)\end{array}$ & $\begin{array}{l}\text { Método experimental de } \\
\text { produzir hipertensão por } \\
\text { meio de isquemia renal }\end{array}$ \\
\hline $1941[1]$ & $\begin{array}{l}\text { Ludgero da Cunha } \\
\text { Motta (1888-1967) }\end{array}$ & U. São Paulo & $\begin{array}{l}\text { Irvine Page } \\
(1901-1991)\end{array}$ & $\begin{array}{l}\text { Estudos sobre hipertensão } \\
\text { arterial experimental }\end{array}$ \\
\hline 1946 & $\begin{array}{l}\text { Henrique de Brito } \\
\text { Belford Roxo } \\
(1877-1969)\end{array}$ & U. Rio de Janeiro & $\begin{array}{l}\text { Manoel de Abreu } \\
(1891-1962)\end{array}$ & $\begin{array}{l}\text { Introdução da fotografia } \\
\text { de radiologia coletiva } \\
\text { "abreugrafia" }\end{array}$ \\
\hline 1946 & $\begin{array}{l}\text { Alfredo Alberto Pereira } \\
\text { Monteiro (1891-1961) }\end{array}$ & U. Rio de Janeiro & Manoel de Abreu & $"$ \\
\hline 1946 & $\begin{array}{l}\text { Arnaldo de Morais } \\
(1893-1961)\end{array}$ & U. Rio de Janeiro & Manoel de Abreu & $"$ \\
\hline
\end{tabular}


Tabela 2: Relação dos cientistas brasileiros convidados para indicar candidatos ao Prêmio Nobel de Fisiologia ou Medicina, bem como dos três cientistas de outras nacionalidades que indicaram candidatos brasileiros ao Prêmio Nobel na mesma categoria, instituição de origem do convidado no ano do convite, ano da indicação e nome do indicado com sua respectiva contribuição, com base no banco de dados da Fundação Nobel, disponível para o período 1901-1953 (cont.)

\begin{tabular}{|c|c|c|c|c|}
\hline Ano & Nomeador & Instituição & Indicado & Contribuição \\
\hline 1946 & $\begin{array}{l}\text { Ugo Pinheiro } \\
\text { Guimarães } \\
\text { (1901-1992) }\end{array}$ & U. Rio de Janeiro & Manoel de Abreu & $"$ \\
\hline 1946 & $\begin{array}{l}\text { Agenor Guimarães } \\
\text { Porto (1880-1964) }\end{array}$ & U. Rio de Janeiro & $\begin{array}{l}\text { Bernardo Albert } \\
\text { Houssay } \\
(1887-1971)\end{array}$ & $\begin{array}{l}\text { Trabalho sobre secreção } \\
\text { endócrina, papel do rim na } \\
\text { hipertonia arterial e veneno } \\
\text { de cobra }\end{array}$ \\
\hline 1947 & $\begin{array}{l}\text { Agenor Guimarães } \\
\text { Porto }\end{array}$ & U. Rio de Janeiro & $\begin{array}{l}\text { Bernardo Albert } \\
\text { Houssay }\end{array}$ & $"$ \\
\hline 1949 & $\begin{array}{l}\text { Ernesto de Souza } \\
\text { Campos (1882-1970) }\end{array}$ & U. São Paulo & $\begin{array}{l}\text { Antônio C. de Abreu } \\
\text { Freire Egas Moniz } \\
(1874-1955)\end{array}$ & $\begin{array}{l}\text { Tratamento cirúrgico de } \\
\text { doenças mentais funcionais. } \\
\text { Diagnóstico de tumores } \\
\text { cerebrais por meio da } \\
\text { encefalografia arterial }\end{array}$ \\
\hline 1949 & $\begin{array}{l}\text { Jayme Regallo Pereira } \\
(1893-1963)\end{array}$ & U. São Paulo & $\begin{array}{l}\text { Antônio C. de Abreu } \\
\text { Freire Egas Moniz }\end{array}$ & $"$ \\
\hline 1949 & Renato Locchi & U. São Paulo & $\begin{array}{l}\text { Antônio C. de Abreu } \\
\text { Freire Egas Moniz }\end{array}$ & $"$ \\
\hline 1950 & $\begin{array}{l}\text { Antônio de Almeida } \\
\text { Prado }\end{array}$ & U. São Paulo & $\begin{array}{l}\text { Antônio C. de Abreu } \\
\text { Freire Egas Moniz }\end{array}$ & $\begin{array}{l}\text { Trabalho sobre tratamento } \\
\text { cirúrgico de distúrbios } \\
\text { mentais e sobre angiografia } \\
\text { cerebral }\end{array}$ \\
\hline 1950 & $\begin{array}{l}\text { Raul Briquet } \\
(1887-1953)\end{array}$ & U. São Paulo & $\begin{array}{l}\text { Edwin J. Cohn } \\
(1892-1953)\end{array}$ & $\begin{array}{l}\text { Fracionamento e uso } \\
\text { terapêutico de proteínas } \\
\text { plasmáticas }\end{array}$ \\
\hline 1951 & $\begin{array}{l}\text { Antônio C. de Abreu } \\
\text { Freire Egas Moniz }\end{array}$ & U. Lisboa, Portugal & Manoel de Abreu & $\begin{array}{l}\text { Fotografia de raio } X \\
\text { sistemático coletivo }\end{array}$ \\
\hline 1953 & $\begin{array}{l}\text { Francisco R. D'Ovidio } \\
\text { [2] }\end{array}$ & $\begin{array}{l}\text { Universidad Nacional } \\
\text { de La Plata, Argentina }\end{array}$ & Manoel de Abreu & Não especificada \\
\hline 1953 & $\begin{array}{l}\text { Paulo Q. T. Tibiriçá } \\
\text { (1903-1985) }\end{array}$ & $\begin{array}{l}\text { U. Rio Grande do Sul } \\
\text { [8] }\end{array}$ & $\begin{array}{l}\text { Hans Selye } \\
(1907-1982)\end{array}$ & Não especificada \\
\hline 1953 & $\begin{array}{l}\text { Paulo M. Moreira } \\
(1915-1974)\end{array}$ & U. Rio Grande do Sul & Hans Selye & Não especificada \\
\hline 1953 & $\begin{array}{l}\text { Luiz Francisco Guerra } \\
\text { Blessmann (1891-1972) }\end{array}$ & U. Rio Grande do Sul & Hans Selye & Não especificada \\
\hline
\end{tabular}

Fonte: Fundação Nobel. Disponível em: http://www.nobelprize.org/nomination/archive/list.php. Acesso em: 15 maio 2017.

U. $=$ Universidade de

[1] Não houve premiação em 1921, 1925 e 1941.

[2] Não constam outras informações no banco de dados da Fundação Nobel, não sendo possível encontrar mais informações nos sites de busca mais conhecidos, como, por exemplo, Google.

[3] Situada na cidade de Rio de Janeiro, passou a fazer parte da recém-criada Universidade do Rio de Janeiro, em 1920.

[4] Atual Universidade Federal da Bahia.

[5] Posteriormente, Universidade do Brasil; atual Universidade Federal do Rio de Janeiro.

[6] Atual Universidade de São Paulo.

[7] Atual Universidade Federal de Minas Gerais.

[8] Atual Universidade Federal do Rio Grande do Sul. 
realizados em países europeus e nos EUA e, em 1926, a convite de Albert Calmette (18631933), um dos descobridores do bacilo de Calmette-Guérin (BCG, utilizado na vacina contra a tuberculose), fez demonstrações de suas pesquisas sobre o bacilo da tuberculose no Institut Pasteur. As ligações de Fontes com pesquisadores do Institut Pasteur podem ter sido decisivas para que um dos cientistas daquela instituição, Michel Weinberg, tenha indicado o nome do brasileiro para a premiação em 1934. Fontes, que havia trabalhado no Instituto Oswaldo Cruz a partir de 1903, foi nomeado diretor da instituição após a morte de Carlos Chagas, em 1934, e permaneceu no cargo até 1942, falecendo no ano seguinte (Souza Araujo, 1943).

Diferentemente de Chagas e Fontes, designados por contribuições específicas, Adolfo Lutz foi indicado ao Prêmio Nobel de Fisiologia ou Medicina em 1938 (Tabela 1) pelo conjunto de sua produção científica sobre diversas doenças (lepra, esporotricose, febre amarela, malária). A indicação foi feita por um nomeador brasileiro (Tabela 2), apesar das estreitas relações de Lutz com pesquisadores, universidades, museus e institutos de pesquisa europeus e norte-americanos (Benchimol, 2003; Benchimol, Sá, 2005).

Único entre os brasileiros indicados que não passou pelo Instituto Oswaldo Cruz, Manoel Dias de Abreu recebeu quatro indicações em 1946, uma em 1951 e uma em 1953 para o Prêmio Nobel de Fisiologia ou Medicina (Tabela 1), pela introdução da fotografia de radiologia coletiva, a abreugrafia. As indicações de 1946 foram feitas por professores da Faculdade de Medicina da Universidade do Rio de Janeiro, e as de 1951 e 1953, por nomeadores estrangeiros (Tabela 2). Manoel de Abreu, após ter se formado em medicina, no Rio de Janeiro, especializou-se em radiologia, em Paris, permanecendo na capital francesa de 1915 a 1922 (Oliveira, 2012). Seu interesse pela então emergente especialidade de radiologia parece ter sido motivado quando estagiou no Hôtel-Dieu, em 1916, e teve a oportunidade de observar um paciente com tuberculose avançada identificada no exame radiológico do tórax, mas que não havia mostrado alterações à percussão e ausculta durante o exame clínico. A contradição chocante entre os achados clínico e radiológico teve um grande significado para Manoel de Abreu (Bedrikow, 2001).

Em 1919, em outro hospital parisiense, o Hospital Laennec, ele visualizou pela primeira vez na fotografia do écran fluorescente o meio de realizar o exame do tórax em massa e por um custo baixo, com a finalidade de detectar precocemente a tuberculose pulmonar. Naquela ocasião obstáculos técnicos o impediram de desenvolver essa nova técnica. Ao retornar ao Rio de Janeiro, em 1922, encontrou a cidade assolada por uma epidemia de tuberculose. Por meio de sua influência, junto com o primeiro dispensário organizado na então capital do país, foi instalado o primeiro Serviço de Radiologia destinado ao diagnóstico da tuberculose. Posteriormente, na década de 1930, assumiu, a pedido do médico e prefeito Pedro Ernesto (1884-1942), a chefia do Serviço de Radiologia do Hospital Jesus.

Após duas tentativas frustradas, em 1936 ele conseguiu desenvolver a radiofotografia do écran fluoroscópico, ou tela fluorescente, um meio de realizar o exame do tórax em larga escala e com baixo custo para detectar a tuberculose pulmonar e outras doenças pulmonares. Combinando as técnicas de radiologia e de fotografia, o aparelho emitia um feixe de raios $X$, que sensibilizava uma tela que se tornava fluorescente e produzia uma imagem visível a olho nu, captada por uma câmera fotográfica. A imagem era então 
registrada em filmes comuns de $35 \mathrm{~mm}$ ou $70 \mathrm{~mm}$. O filme de $35 \mathrm{~mm}$, embora de menor custo e o preferido por Manoel de Abreu, exigia o uso de lentes de aumento especiais para a interpretação do exame, pois as imagens obtidas eram cópias em miniaturas de radiografias do pulmão. A nova técnica radiológica foi adotada rapidamente em outras cidades do Brasil e de outros países do continente americano e da Europa, passando a ser denominada "abreugrafia" no Brasil em 1939, embora em outros países tenha recebido diversas outras denominações, como mass radiography no Reino Unido e miniature chest radiograph nos EUA. Manoel de Abreu publicou diversos artigos sobre sua técnica em revistas nacionais e internacionais e realizou inúmeras conferências médicas em Brasil, Argentina, Uruguai, EUA e alguns países europeus. Ele recebeu diversos prêmios e honrarias de instituições europeias e estadunidenses e é considerado uma das grandes personalidades da medicina brasileira.

Nas décadas seguintes, entretanto, começaram a surgir questionamentos sobre o uso indiscriminado da abreugrafia, muitas vezes por exigência legal para ingresso em novos empregos, como no Brasil. O conhecimento de que mesmo doses mínimas de radiações podem condicionar sérios riscos somáticos e genéticos, a verificação de que a pesquisa do bacilo da tuberculose no escarro é do ponto de vista epidemiológico mais barata e segura, uma vez que elimina os casos de tuberculose inativa e de pneumopatias inespecíficas, e o pronunciamento contrário à abreugrafia em massa pela Organização Mundial da Saúde em 1974 (OMS, 1974, p.16) acabaram por limitar seu uso em diversos países. A partir de 1976, surgiram propostas de abolição da abreugrafia sistemática, com a eliminação, na legislação brasileira, dos dispositivos que a tornavam obrigatória em numerosas eventualidades (Algranti, Ali, Cuginotti, 1986; Gikovate, Nogueira, 1976). No entanto, a abreugrafia continua a ser utilizada em alguns países para detectar a presença de tuberculose em grupos considerados de alto risco, como novos imigrantes e refugiados procedentes de países com alta prevalência da doença (Bonvin, Zellweger, 1992) e em prisões (Jones, Schaffner, 2001).

É interessante verificar quem foram os cientistas laureados e os não laureados mais indicados ao Prêmio Nobel de Fisiologia ou Medicina nos anos em que houve indicações de cientistas brasileiros à premiação. A Tabela 3 mostra a relação dos laureados e dos três primeiros não laureados com maior número de indicações, com base no banco de dados da Fundação Nobel disponível para o período de 1901-1953, incluindo o ano e o número de indicações, e a contribuição pela indicação (Nomination Database, s.d.).

Os quatro cientistas brasileiros indicados para o Prêmio Nobel de Fisiologia ou Medicina tiveram número muito inferior de indicações aos mais indicados nos respectivos anos. Embora os cientistas com maior número ou grande número de indicações tenham sido, com certa frequência, os laureados com o Nobel, isso nem sempre ocorreu. Em cinco dos seis anos em que houve premiação do Nobel de Fisiologia ou Medicina com a indicação de brasileiros, o prêmio coube a cientistas que tiveram número inferior de indicações comparado aos três primeiros que receberam maior número de indicações $(1934,1938$, 1946, 1951 e 1953). E dois premiados com o Nobel de Fisiologia ou Medicina, Corneille Heymans em 1938 e Max Theiler em 1951, receberam apenas uma indicação no ano da premiação. Ou seja, o baixo número de indicações por si só não seria um empecilho para que os brasileiros efetivamente fossem condecorados. 
Tabela 3: Relação dos cientistas laureados e não laureados com o maior número de indicações ao Prêmio Nobel de Fisiologia ou Medicina [1] nos anos em que houve indicações de cientistas brasileiros à premiação, com a contribuição de cada um, com base no banco de dados da Fundação Nobel disponível para o período 1901-1953

\begin{tabular}{|c|c|c|c|}
\hline Ano & Indicado & $\begin{array}{l}\text { Número de } \\
\text { indicações }\end{array}$ & Contribuição \\
\hline 1913 & $\begin{array}{l}\text { Charles Robert Richet (1850-1935) [2] } \\
\text { Carlo Forlanini (1847-1918) } \\
\text { Heinrich Quincke (1842-1922) } \\
\text { Jean-Louis Prévost (1838-1927) }\end{array}$ & $\begin{array}{l}9 \\
8 \\
7 \\
7\end{array}$ & $\begin{array}{l}\text { Trabalho sobre anafilaxia } \\
\text { Introdução do pneumotórax artificial para o } \\
\text { tratamento da tuberculose pulmonar } \\
\text { Introdução da punção lombar } \\
\text { Trabalho sobre paralisia infantil, desvio ocular } \\
\text { na hemiplegia, corda do tímpano, antagonismos } \\
\text { entre alguns venenos, envenenamento pelo } \\
\text { mercúrio, efeito de medicamentos sobre a } \\
\text { secreção biliar, contrações fibrilares no coração } \\
\text { submetido a eletroestimulação }\end{array}$ \\
\hline 1921 [3] & $\begin{array}{l}\text { Charles Sherrington (1857-1952) [4] } \\
\text { Eugène Gley (1857-1930) }\end{array}$ & $\begin{array}{l}19 \\
11\end{array}$ & $\begin{array}{l}\text { Trabalho sobre a atividade reflexa no sistema } \\
\text { nervoso } \\
\text { Trabalho sobre o papel preventivo do fígado } \\
\text { na coagulação, a função da glândula tireoide, a } \\
\text { descoberta da paratireoide e de suas funções, } \\
\text { o efeito curativo do estrato da tireoide na } \\
\text { secreção endócrina } \\
\text { Descoberta do soro antidiftérico }\end{array}$ \\
\hline 1934 & $\begin{array}{l}\text { George Hoyt Whipple (1878-1976) [2] } \\
\text { George Richards Minot (1885-1950) [2] } \\
\text { William Parry Murphy (1892-1987) [2] } \\
\text { Gaston Ramon (1886-1963) } \\
\text { Rudolf Weigl (1883-1957) } \\
\text { Louis E. Lapicque (1866-1952) }\end{array}$ & $\begin{array}{l}6 \\
12 \\
3 \\
24 \\
17\end{array}$ & $\begin{array}{l}\text { Descoberta da terapia do fígado nos casos de } \\
\text { anemia } \\
\text { " } \\
\text { Descoberta de anatoxinas } \\
\text { Trabalho sobre tifo, especialmente sobre o papel } \\
\text { da Rickettsia prowazeki e imunização contra a } \\
\text { doença } \\
\text { Trabalho sobre cronaxia }\end{array}$ \\
\hline 1938 & $\begin{array}{l}\text { Corneille Heymans (1892-1968) [2] } \\
\text { Gaston Ramon (1886-1963) } \\
\text { Alfred Newton Richards (1876-1966) } \\
\text { David Keilin (1887-1963) }\end{array}$ & $\begin{array}{l}1 \\
23 \\
18 \\
8\end{array}$ & $\begin{array}{l}\text { Trabalho sobre o papel dos pressorreceptores e } \\
\text { quimiorreceptores do seio carotídeo } \\
\text { Trabalho sobre anatoxinas, especialmente a } \\
\text { vacinação contra difteria e tétano } \\
\text { Trabalho sobre a fisiologia dos rins } \\
\text { Trabalho sobre citocromo e o papel fisiológico } \\
\text { dos compostos hemes }\end{array}$ \\
\hline 1946 & $\begin{array}{l}\text { Hermann Joseph Muller (1890-1967) [2] } \\
\text { Alexander Fleming (1881-1955) } \\
\text { Gaston Ramon (1886-1963) } \\
\text { Wendell Stanley (1904-1971) }\end{array}$ & $\begin{array}{l}4 \\
10 \\
7 \\
7\end{array}$ & $\begin{array}{l}\text { Descoberta da produção de mutações por meio } \\
\text { da irradiação pelo raio X } \\
\text { Descoberta da penicilina e seu efeito curativo } \\
\text { em várias doenças infecciosas } \\
\text { Trabalho sobre anatoxinas, especialmente a } \\
\text { vacinação contra difteria e tétano } \\
\text { Cristalização de vírus }\end{array}$ \\
\hline 1951 & $\begin{array}{l}\text { Max Theiler (1899-1972) [2] } \\
\text { Gaston Ramon (1886-1963) } \\
\text { Helen Taussig (1898-1986) } \\
\text { Alfred Blalock (1899-1964) }\end{array}$ & $\begin{array}{l}1 \\
10 \\
7 \\
6\end{array}$ & $\begin{array}{l}\text { Descoberta relativa à febre amarela e como } \\
\text { combatê-la } \\
\text { Trabalho sobre anatoxinas contra difteria } \\
\text { Trabalho sobre o tratamento cirúrgico de } \\
\text { malformações do coração } \\
\text { Trabalho sobre o tratamento cirúrgico de } \\
\text { distúrbios cardíacos congênitos }\end{array}$ \\
\hline
\end{tabular}


Tabela 3: Relação dos cientistas laureados e não laureados com o maior número de indicações ao Prêmio Nobel de Fisiologia ou Medicina [1] nos anos em que houve indicações de cientistas brasileiros à premiação, com a contribuição de cada um, com base no banco de dados da Fundação Nobel disponível para o período 1901-1953 (cont.)

\begin{tabular}{|l|l|l|l|}
\hline Ano & Indicado & $\begin{array}{l}\text { Número de } \\
\text { indicações }\end{array}$ & Contribuição \\
\hline & $\begin{array}{l}\text { Hans Adolf Krebs (1900-1981) [2] } \\
\text { Fritz A Lipmann (1899-1986) [2] }\end{array}$ & 7 & $\begin{array}{l}\text { Descoberta do ciclo do ácido cítrico } \\
\text { Descoberta da coenzima A e sua importância no } \\
\text { metabolismo intermediário } \\
\text { Métodos cirúrgicos para o estudo da fisiologia } \\
\text { do sistema nervoso simpático } \\
\text { Descoberta da Atabrine (hidrocloreto de } \\
\text { quinacrina), um agente antimalárico } \\
\text { Trabalho sobre a síntese de sulfonamidas } \\
\text { Descoberta da Atabrine (hidrocloreto de } \\
\text { quinacrina), um agente antimalárico }\end{array}$ \\
\hline
\end{tabular}

Fonte: Fundação Nobel. Disponível em: http://www.nobelprize.org/nomination/archive/list.php. Acesso em: 29 ago. 2017.

[1] A lista inclui os três cientistas que receberam maior número de indicações. Nos casos em que o laureado recebeu menos indicações do que os três cientistas com maior número de indicações, a lista inclui os laureados e os três cientistas que receberam maior número de indicações. O número total de cientistas indicados para a premiação em cada ano foi: 1913 (64 cientistas); 1921 (43); 1934 (76); 1938 (53); 1946 (34); 1951 (89); 1953 (105).

[2] Laureado com o Prêmio Nobel no ano indicado.

[3] Não houve premiação em 1921. Uma possível explicação para a não concessão da premiação naquele ano pode ser encontrada em Pittella (2009).

[4] Sherrington recebeu o Prêmio Nobel em 1932.

Ao longo da primeira metade do século XX, o rápido desenvolvimento das ciências básicas e clínicas da medicina ampliou enormemente o leque de descobertas científicas que poderiam ser indicadas e contempladas pelo Nobel. Como se pode ver resumidamente na Tabela 3 e na compilação publicada sobre o tipo ou natureza da descoberta pelos quais os cientistas foram laureados no período de 1901 a 1953, a partir da década de 1920 a premiação passou a contemplar preferencialmente as descobertas sobre vitaminas, hormônios, metabolismo intermediário, fisiologia e neurobiologia, entre outras (Lindsten, Ringertz, 2001). Nenhuma das contribuições dos brasileiros indicados esteve associada a essas áreas de vanguarda da pesquisa médico-científica. Ligaram-se, no caso de Chagas, Fontes e Lutz, a investigações concernentes principalmente à etiologia e ao modo de transmissão de doenças infecciosas e, no caso de Manoel de Abreu, ao desenvolvimento de métodos diagnósticos em medicina, no caso, para auxiliar no diagnóstico de doenças pulmonares, particularmente a tuberculose, também objeto de estudo de Fontes. Ao longo do período de 1901 a 1953, a única premiação com o Nobel de Fisiologia ou Medicina contemplando o desenvolvimento de um método diagnóstico foi para Willem Einthoven (1860-1927), que recebeu a premiação em 1924 pela descoberta do eletrocardiograma.

Interessante mencionar que a investigação científica sobre a tuberculose motivou a indicação e a premiação de outros cientistas: o pneumotórax artificial foi o que levou à indicação de Carlo Forlanini ao Nobel em Fisiologia ou Medicina em 1913 (no mesmo ano da primeira indicação de Chagas. Ver Tabela 3), e em vários outros anos, embora Forlanini não tenha obtido a premiação. A descoberta da estreptomicina como tratamento eficaz da tuberculose levou à condecoração do bioquímico e microbiologista Selman Waksman (1888-1973) com o Prêmio Nobel em Fisiologia ou Medicina em 1952. Um dos campeões 
de indicações para a premiação pelo Nobel em Fisiologia ou Medicina, embora não tenha sido nunca laureado, foi Alberto Calmette, que desenvolveu a primeira vacina contra a tuberculose, a BCG: ele recebeu 77 indicações no período de 1907-1934.

\section{Cientistas brasileiros convidados para indicar candidatos ao Prêmio Nobel de Fisiologia ou Medicina, bem como cientistas de outras nacionalidades que indicaram candidatos brasileiros ao Prêmio Nobel nessa categoria}

A Tabela 2 mostra a relação dos cientistas brasileiros convidados para indicar candidatos ao Prêmio Nobel de Fisiologia ou Medicina, bem como a dos três cientistas de outras nacionalidades que indicaram candidatos brasileiros ao Prêmio Nobel nessa mesma categoria, ano da indicação, instituição de origem do convidado no ano do convite e nome do indicado com sua respectiva contribuição, com base no banco de dados da Fundação Nobel, disponível para o período de 1901 a 1953 (Nomination Database, s.d.).

Foram convidados para indicar candidatos ao Prêmio Nobel de Fisiologia ou Medicina 24 cientistas brasileiros. A maioria era afiliada a instituições universitárias de São Paulo (dez nomeadores) e Rio de Janeiro (oito), e, os restantes, afiliados a instituições do Rio Grande do Sul (três nomeadores), Bahia (um) e Minas Gerais (um). Um dos nomeadores brasileiros, Henrique da Rocha Lima, na época do convite, estava trabalhando no Institut für Schiffs- und Tropenkrankheiten, em Hamburgo, na Alemanha, onde permaneceu de 1909 a 1927 (Silva, 2013).

Três cientistas brasileiros foram convidados duas vezes para indicar candidatos ao Nobel (Agenor Guimarães Porto, Renato Locchi e Antônio de Almeida Prado), e apenas um (Cunha Motta, em 1941) indicou dois nomes no mesmo ano. Três dos quatro cientistas brasileiros indicados ao Prêmio Nobel de Fisiologia ou Medicina, Carlos Chagas, Adolfo Lutz e Manoel de Abreu, foram indicados por compatriotas. Manoel de Abreu recebeu também duas indicações de cientistas de outros países: uma de Antônio C. de Abreu Freire Egas Moniz, da Universidade de Lisboa, Portugal; e uma de Francisco R. D'Ovidio, da Universidad Nacional de La Plata, Argentina. E a única indicação recebida por Antônio Cardoso Fontes foi de Michel Weinberg, do Institut Pasteur, de Paris, já comentada.

Com cinco indicações, o fisiologista norte-americano Walter Bradford Cannon, reconhecido pelas pesquisas sobre o processo digestivo, homeostase fisiológica e mecanismos do sistema nervoso, foi quem recebeu o maior número de indicações por cientistas brasileiros, seguido por Antônio C. de Abreu Freire Egas Moniz (quatro indicações), Manoel de Abreu (quatro), Hans Selye (três), Bernardo Albert Houssay (duas), Carlos Chagas (duas) e os demais, uma indicação cada. Embora na indicação de Hans Selye, em 1953, os nomeadores brasileiros não tenham especificado o motivo da indicação (Tabela 2), Selye era internacionalmente reconhecido pelo trabalho desenvolvido na endocrinologia e na síndrome de adaptação ao estresse. Como se pode ver ainda na Tabela 2, houve forte tendência de indicação dos mesmos candidatos por membros das mesmas instituições em 1941, 1946, 1949 e 1953. Nota-se que, apesar de as contribuições dos brasileiros indicados à premiação pelo Nobel concentrarem-se na etiologia, transmissão e diagnóstico de doenças infecciosas, as indicações de pares estrangeiros pelos nomeadores brasileiros no período 
de 1941 a 1953 enfatizaram contribuições em áreas como fisiologia, hormônios, métodos diagnósticos e neurocirurgia (Tabela 2).

Dos cientistas indicados por brasileiros, apenas dois foram laureados com o Prêmio Nobel: Bernardo Albert Houssay, laureado em 1947, com 11 indicações, uma delas por Agenor Guimarães Porto; e Antônio C. de Abreu Freire Egas Moniz, laureado em 1949, com nove indicações, o maior número de indicações por um cientista naquele ano, cinco delas de cientistas portugueses, três de brasileiros (Ernesto de Souza Campos, Jayme Regallo Pereira e Renato Locchi) e uma de um cientista da Dinamarca. Admite-se que as indicações dos brasileiros tenham sido de grande importância, pois constituíram 3/4 das nomeações estrangeiras, fornecendo, juntamente com a indicação do dinamarquês, o contingente internacional de nomeadores (Correia, 2014). É possível que o reconhecimento de Egas Moniz pelo apoio dos colegas brasileiros tenha influenciado sua decisão de indicar Manoel de Abreu para a premiação do Nobel em 1951.

Todos os brasileiros convidados foram renomados professores em suas respectivas instituições de ensino, que se destacavam entre as mais prestigiadas do país, tendo contribuído para o ensino, a pesquisa e a extensão em suas especialidades médicas básicas, clínicas e cirúrgicas, além de a maioria deles ter também participado de cargos de direção de instituições universitárias. As faculdades de medicina às quais os nomeadores brasileiros eram afiliados foram criadas em 1808 (Bahia e Rio de Janeiro), 1898 (Rio Grande do Sul), 1911 (Minas Gerais) e 1912 (São Paulo).

Três dos primeiros brasileiros indicados como nomeadores do Prêmio Nobel, Pirajá da Silva, Hilário de Gouvêa e Henrique da Rocha Lima, exemplificam diferentes tipos de ligação entre cientistas do Brasil e os de países europeus naquela época. No período entre 1908 e 1912, Pirajá da Silva, reconhecido pela descrição do verme adulto do Schistosoma mansoni, em 1908, fez cursos na Faculdade de Medicina e no Institut Pasteur, em Paris, onde aprimorou sua formação com o médico e parasitologista Raphaël Blanchard (1857-1919) e o patologista Maurice Letulle (1853-1929), e no Institut für Schiffs- und Tropenkrankheiten, em Hamburgo (Prata, 2008). A interação de Pirajá da Silva com cientistas franceses e alemães naquele período pode ter contribuído para a sua escolha como nomeador para o Prêmio Nobel em 1913. Hilário de Gouvêa havia exercido medicina em Paris no período de 1893 a 1899, onde fez curso no Institut Pasteur, e, posteriormente, participado de congressos internacionais da Liga contra a Tuberculose em capitais europeias, em 1901, 1902, 1904 e 1905 (Gouvêa..., s.d.). As fortes ligações de Hilário de Gouvêa com cientistas e instituições europeias naquele período podem ter sido determinantes para sua indicação como nomeador em 1921, mesmo após tantos anos. Rocha Lima, ao ser convidado como nomeador, em 1925, dirigia o Departamento de Patologia do Institut für Schiffs- und Tropenkrankheiten, em Hamburgo, onde permaneceu de 1909 a 1927. Na época do convite, ele já era reconhecido internacionalmente pelos estudos do agente etiológico do tifo epidêmico realizados durante a Primeira Guerra Mundial (Silva, 2013). As relações de Rocha Lima com instituições científicas europeias e o fato de estar ligado a uma delas, de grande reputação, certamente influenciaram a sua escolha como nomeador.

Não causa muita surpresa, portanto, o fato de que 18 dos 24 nomeadores brasileiros tenham sido afiliados a faculdades de medicina que, na primeira metade do século passado, 
já se destacavam na pesquisa científica, seja com alguma tradição (Faculdade de Medicina da Universidade do Rio de Janeiro), seja desenvolvida mais recentemente (Faculdade de Medicina da Universidade de São Paulo). As relações científicas e profissionais entre nomeadores e indicados brasileiros podem ser exemplificadas no caso da indicação de Manoel de Abreu. Ele implantou vários serviços de radiologia em hospitais do Rio de Janeiro e ocupou a presidência de sociedades médicas científicas sediadas na cidade, o que pode ter contribuído para a sua indicação ao Prêmio Nobel em 1946 por quatro professores de especialidades clínicas e cirúrgicas da Faculdade de Medicina da Universidade do Rio de Janeiro.

Dois exemplos da relação entre nomeadores brasileiros e de indicados estrangeiros à premiação pelo Nobel são as indicações de Egas Moniz e Walter B. Cannon. No caso de Egas Moniz, a indicação de seu nome foi proposta pela delegação brasileira durante a $1^{\text {a }}$ Conferência Internacional de Psicocirurgia, realizada em Lisboa, no verão de 1948. A proposta, submetida ao plenário pelo psiquiatra paulista Antônio Carlos Pacheco e Silva (1898-1988), foi aprovada por aclamação (Correia, 2014). Pacheco e Silva, professor de psiquiatria da Faculdade de Medicina da Universidade de São Paulo, seguindo orientação da tribuna da conferência, no seu retorno ao Brasil fez diligências a favor de Egas Moniz. Justamente naquele ano seus colegas docentes da faculdade de medicina, os já citados Ernesto de Souza Campos, Jayme Regallo Pereira e Renato Locchi, foram credenciados para indicar candidatos ao Nobel e indicaram Egas Moniz à premiação, provavelmente influenciados pelas diligências de Pacheco e Silva, contribuindo para que o cientista português fosse laureado.

No caso de Walter B. Cannon, a relação com um dos nomeadores brasileiros, Franklin Augusto de Moura Campos, foi mais direta. Moura Campos foi professor de fisiologia da Faculdade de Medicina da Universidade de São Paulo, onde criou em seu laboratório o maior centro de pesquisas em nutrição da América Latina. Ele foi bolsista da Fundação Rockefeller entre 1926 e 1928 e, em parte desse período, trabalhou no laboratório de fisiologia da Faculdade de Medicina de Harvard dirigido por Walter B. Cannon (Begliomini, s.d.). Essa relação de trabalho na mesma disciplina básica médica entre um nomeador e um indicado à premiação ajuda a explicar por que cinco dos seis nomeadores da mesma instituição (Faculdade de Medicina da Universidade de São Paulo), incluindo Moura Campos, indicaram Walter B. Cannon ao Prêmio Nobel de Fisiologia ou Medicina em 1941.

Um último comentário deve ser feito sobre a comparação da participação de cientistas brasileiros indicados à premiação e como nomeadores nas duas categorias da premiação pelo Nobel ora em análise: a física e a fisiologia ou medicina. A indicação de apenas um brasileiro (Lattes) e a presença de apenas um brasileiro como nomeador (Carlos Chagas Filho), médico com formação em física biológica, na categoria de física, no período examinado (19011966), conforme já mencionado, são explicadas pela incipiente ciência da física no Brasil, especialmente na época da indicação de Lattes à premiação. Por outro lado, embora tenha sido pequeno o número de indicados à premiação (quatro) e de nomeadores brasileiros (24) na categoria de fisiologia ou medicina, no período examinado (1901-1953), esses dados refletem o desenvolvimento da pesquisa científica nas mais antigas faculdades de medicina e institutos de pesquisa brasileiros e a integração de cientistas dessas instituições com a 
comunidade científica internacional, particularmente a partir da década de 1940, quando aumentou substancialmente a participação de brasileiros como nomeadores do Nobel (Tabela 2). Diferentemente das décadas anteriores, além do aumento do número de nomeadores, vários professores de uma mesma instituição passaram a ser convidados como nomeadores em um mesmo ano, refletindo a ampliação da rede de conexões entre os cientistas brasileiros e os de universidades e institutos de pesquisa europeus e norte-americanos. Por outro lado, o pequeno número de indicações de brasileiros por nomeadores brasileiros (sete) e estrangeiros (três) contrasta com o grande número de indicações de estrangeiros (21) por nomeadores brasileiros (17) [Tabela 2], dados esses que podem ser interpretados de duas maneiras: (1) o desconhecimento ou o não reconhecimento das descobertas dos cientistas brasileiros indicados ao Nobel pela quase totalidade da comunidade científica internacional representada pelos nomeadores estrangeiros e pelo Comitê Nobel; (2) no período de 1901 a 1953, a produção científica brasileira foi relativamente pequena, fato reconhecido pela grande maioria dos nomeadores brasileiros.

\section{Considerações finais}

Na maior parte do período coberto desde a criação do Nobel, em 1901, a produção científica dos países em desenvolvimento teve pouca visibilidade internacional. Nas últimas décadas, graças ao crescimento da renda nacional bruta per capita, ao aumento do investimento em desenvolvimento e pesquisa e à globalização, houve grande crescimento da produção científica na China e em outras potências científicas emergentes como Índia, Coreia do Sul, Singapura e Brasil (Knowledge..., 2011). É possível admitir que esse crescimento tenha sido acompanhado de maior visibilidade dos cientistas desses países e, portanto, do reconhecimento deles pela comunidade científica internacional, ampliando assim as chances de aumento do número de nomeadores e de indicados procedentes desses países para a premiação do Nobel. Como descrito anteriormente, o número de nomeadores brasileiros já havia aumentado substancialmente a partir da década de 1940, comparado com o das décadas anteriores.

A análise do processo de avaliação em ciência, exemplificada pela premiação do Nobel, é de grande valor para os historiadores da ciência, tendo em vista o conhecimento dos fatores que condicionavam e ainda condicionam as escolhas de nomeadores, indicados e ganhadores do prêmio (Pittella, 2009, 2012, p.240-251). À medida que houver acesso aos arquivos do Prêmio Nobel referentes à segunda metade do século XX, será oportuno analisar esses documentos tendo em vista a melhor compreensão do processo da inserção dos brasileiros na mais prestigiada premiação mundial em ciência.

Uma pesquisa no acervo documental dos arquivos do Prêmio Nobel certamente trará elementos qualitativos muito mais ricos para avaliar justificativas, alianças, conflitos e motivações envolvidos na indicação dos brasileiros ao Prêmio Nobel. Em tempos em que se atenta para a importância da internacionalização da ciência brasileira, um estudo histórico do que se considera um dos elementos emblemáticos do internacionalismo em ciência, com seus vieses e determinações de naturezas diversas, ajuda-nos a ter uma perspectiva mais crítica desse processo. Sem desmerecer a importância simbólica do Prêmio Nobel e 
a seriedade dos envolvidos em sua operação, o reconhecimento da qualidade acadêmica pela comunidade científica internacional obedece a injunções que não se restringem à avaliação do conteúdo e do impacto da contribuição científica stricto sensu. Tão importante quanto isso são as redes de relações estabelecidas com os pares estrangeiros - sobretudo dos países desenvolvidos -, o pertencimento nacional e a existência de tradições científicas consideradas emparelhadas com o que se convenciona qualificar como áreas de vanguarda nas diversas disciplinas.

\section{REFERÊNCIAS}

ALGRANTI, Eduardo; ALI, Salim Amed;

CUGINOTTI, Aloisio P.

A inadequação dos exames radiológicos periódicos indiscriminados em saúde ocupacional: resultados do censo de $1984 \mathrm{em}$ uma empresa de grande porte. Revista de Saúde Pública, v.20, n.1, p.26-32. 1986.

ALMEIDA, Darcy Fontoura de.

A contribuição de Carlos Chagas Filho para a institucionalização da pesquisa científica na universidade brasileira. História, Ciências, Saúde Manguinhos, v.19, n.2, p.653-68. 2012.

BARTHOLOMEW, James R.

One hundred years of the Nobel science prizes.

Isis: a journal of the History of Science Society, v.96, n.4, p.625-632. 2005

BEDRIKOW, Rubens.

Manoel de Abreu. Jornal de Pneumologia, v.27, n.1, p.56-58. 2001.

BEGLIOMINI, Hélio.

Franklin Augusto de Moura Campos. Disponível em: http://academiamedicinasaopaulo.org. br/biografias/58/BIOGRAFIA-FRANKLIN-DEMOURA-CAMPOS.pdf. Acesso em: 7 jan. 2017. s.d.

BENCHIMOL, Jaime Larry.

Adolpho Lutz: um esboço biográfico. História, Ciências, Saúde - Manguinhos, v.10, n.1, p.1383. Disponível em: http://www.scielo.br/ scielo.php?script $=$ sci_arttext\&pid $=$ S0104$59702003000100002 \& \operatorname{lng}=$ en \& $n r m=i s o \& \operatorname{lng}=$ pt. Acesso em: 26 set. 2016. 2003.

BENCHIMOL, Jaime Larry.

Febre amarela: a doença e a vacina, uma história inacabada. Rio de Janeiro: Editora Fiocruz. 2001.

BENCHIMOL, Jaime Larry; SÁ, Magali Romero. Insetos, humanos e doenças: Adolpho Lutz e a medicina tropical. In: Benchimol, Jaime Larry; Sá, Magali Romero (Org.). Febre amarela, malária e protozoologia. (Adolpho Lutz. Obra completa, v.2, livro 1). Rio de Janeiro: Editora Fiocruz. p.43-244. Disponível em: https://www.arca. fiocruz.br/handle/icict/15124. Acesso em: 29 abr. 2017. 2005 .
BONVIN, Louis; ZELLWEGER, Jean-Pierre. Mass miniature X-ray screening for tuberculosis among immigrants entering Switzerland. Tubercle and Lung Disease, v.73, n.6, p.322-325. 1992.

CHANDRASEKHAR, S.; RATNAM, S.

Studies on cell-wall deficient non-acid fast variants of Mycobacterium tuberculosis. Tubercle and Lung Disease, v.73, n.5, p.273-279. 1992.

CORREIA, Manuel.

Egas Moniz e os seus colegas no Brasil: a arquitetura de um Prêmio Nobel. ComCiência n.164. Disponível em: http://comciencia.scielo. br/pdf/cci/n164/09.pdf. Acesso em: 30 set. 2016. 2014.

COUTINHO, Marília; DIAS, João Carlos Pinto. A descoberta da doença de Chagas. Cadernos de Ciência \& Tecnologia, v.16, n.2, p.11-51. 1999.

COUTINHO, Marília; FREIRE JR., Olival; DIAS, João Carlos Pinto.

The noble enigma: Chagas' nominations for the Nobel Prize. Memórias do Instituto Oswaldo Cruz, v.94, supl.1, p.123-129. 1999.

CRAWFORD, Elisabeth (Ed.).

Historical studies in the Nobel archives: the prizes in science and medicine. Tokyo: Universal Academy Press. 2002.

CRAWFORD, Elisabeth.

Nobel: always the winners, never the losers. Science, v.282, n.5392, p.1256-1257. 1998.

CRAWFORD, Elisabeth.

Nationalism and internationalism in science, 18801939: four studies of the Nobel population.

Cambridge: Cambridge University Press. 1992.

CRAWFORD, Elisabeth.

The beginnings of the Nobel Institution: the science prizes, 1901-1915. Cambridge: Cambridge University Press. 1984.

CRAWFORD, Elisabeth; SIME, Ruth Lewin; WALKER, Mark.

A Nobel tale of postwar injustice. Physics Today, v.50, n.9, p.26-32. 1997. 
DARDO, Mauro.

Nobel laureates and twentieth century physics. Cambridge: Cambridge University Press. 2004.

FONTES, Antônio.

Algumas considerações sobre a infeção tuberculosa e o seu respetivo vírus. Memórias do Instituto Oswaldo Cruz, v.2, n.1, p.141-146. 1910.

FRIEDMAN, Robert Marc.

The politics of excellence: behind the Nobel Prize in Science. New York: W.H. Freeman. 2001.

GARIBOLDI, Leonardo; TUCCI, Pasquale. Giuseppe Paolo Stanislao Occhialini (19071993): a short biography. In: Redondi, Pietro et al. (Org.). The scientific legacy of Beppo Occhialini. Bologna: Società Italiana di Fisica; Berlin, Heidelberg: Springer Verlag. p.XI-XXXVII. 2006.

GIKOVATE, Febus; NOGUEIRA, Diogo P. Abreugrafia sistemática em massa: inviabilidade econômica e eventuais perigos da exposição a radiações. Revista de Saúde Pública, v.10, n.1, p.103-110. 1976.

\section{GOUVÊA...}

Gouvêa, Hilário Soares de. Dicionário HistóricoBiográfico das Ciências da Saúde no Brasil (1832-1930). Casa de Oswaldo Cruz/Fiocruz. Disponível em: http://www.dichistoriasaude. coc.fiocruz.br/iah/pt/verbetes/gouhilso.htm. Acesso em: 6 jun. 2017. s.d.

GURGEL, Cristina B.M.F.; MAGDALENA, Christiane Vanessa; PRIOLI, Larissa F. Carlos Chagas e o enigma do Prêmio Nobel. Cadernos de Saúde Coletiva, v.17, n.4, p.799-809. 2009.

\section{HARGITTAI, István.}

The road to Stockholm: Nobel Prizes, science, and scientists. Oxford, New York: Oxford University Press. 2002.

IF...

IF - Instituto de Física. Disponível em: http://200.144.182.66/memoria/por/ unidade/166-Instituto_de_Fisica. Acesso em: 13 dez. 2016.4 set. 2014 .

JONES, Timothy F.; SCHAFFNER, William. Miniature chest radiograph screening for tuberculosis in jails: a cost-effectiveness analysis. American Journal of Respiratory and Critical Care Medicine, v.164, n.1, p.77-81. 2001.

\section{KNOWLEDGE...}

Knowledge, networks and nations: global scientific collaboration in the 21st century. London: The Royal Society. Disponível em: https:// www.snowballmetrics.com/wp-content/ uploads/4294976134.pdf. Acesso em: 12 abr. 2017. 2011.
KROPF, Simone Petraglia; SÁ, Magali Romero. The discovery of Trypanosoma cruzi and Chagas disease (1908-1909): tropical medicine in Brazil. História, Ciências, Saúde - Manguinhos, v.16, supl.1. Disponível em: http://www.scielo.br/scielo.php?pid=S0104$59702009000500002 \&$ script $=$ sci_arttext. Acesso em: 15 dez. 2016. 2009.

LATTES, Celso M.G. et al.

Processes involving charged mesons. Nature, v.159, n.4047, p.694-697. Disponível: https:// www.nature.com/articles/159694a0\#auth-1. Acesso em: 1 out. 2016. 24 maio 1947.

LEMMEL, Birgitta.

The Nobel Foundation: a century of growth and change. Nobelprize.org. Disponível em: http:// www.nobelprize.org/nobel_organizations/ nobelfoundation/history/lemmel/index.html. Acesso em: 26 abr. 2017. 2011.

LEWINSOHN, Rachel.

Prophet in his own country: Carlos Chagas and the Nobel Prize. Perspectives in biology and medicine, v.46, n.4, p.532-549. 2003.

LINDSTEN, Jan; RINGERTZ, Nils.

The Nobel Prize in physiology or medicine. In: Levinovitz, Agneta Wallin; Ringertz, Nils (Ed.). The Nobel prize: the first 100 years. London, Singapore: Imperial College Press and World Scientific Publishing Co. p.111-136. Disponível em: http://nobelprize.org/nobel_prizes/ medicine/articles/lindsten-ringertz-ver/index. html. Acesso em: 15 set. 2016. 2001.

NASCIMENTO, Marcio Luis Ferreira. On the "Missing Letter" to Lattes and the Nobel Prize in Physics. Ciência e Sociedade, CBPF, v.3, n.2, p.35-42. 2015.

\section{NOMINATION AND SELECTION OF \\ MEDICINE...}

Nomination and selection of medicine laureates. Nobelprize.org. Disponível em: http://www. nobelprize.org/nomination/medicine/index. html. Acesso em: 5 abr. 2017. s.d.

NOMINATION AND SELECTION OF PHYSICS... Nomination and selection of physics laureates. Nobelprize.org. Disponível em: http://www. nobelprize.org/nomination/physics. Acesso em: 5 abr. 2017. s.d.

\section{NOMINATION ARCHIVE.}

Nomination archive. Nobelprize.org. Disponível em: http://www.nobelprize.org/nomination/ archive/. Acesso em: 15 mar. 2016. s.d.

\section{NOMINATION DATABASE.}

Nomination database. Nobelprize.org. Disponível em: http://www.nobelprize.org/nomination/ archive/list.php. Acesso em: 15 mar. 2016. s.d. 
NOMINATION DATABASE. COUNTRIES... Nomination database. Countries, cities and universities. Nobelprize.org. Disponível em: https://www.nobelprize.org/nomination/ archive/country.php. Acesso em: 29 ago. 2017. s.d.

NOVELLO, Mário.

Cesar Lattes, a descoberta do méson- $\varpi$ e a física de partículas. Cosmos \& Contexto, n.3. Disponível em: http://cosmosecontexto.org.br/cesar-lattesa-descoberta-do-meson-\%CF\% 80-e-a-fisica-departiculas/. Acesso em: 1 out. 2016. 2012.

OLIVEIRA, Oldair de.

$O$ mestre das sombras: um raio $\mathrm{X}$ histórico de Manoel de Abreu. São Paulo: SPR. 2012.

OMS.

Organización Mundial de la Salud. Serie de Informes Técnicos de la OMS, n.552. Comité de Expertos de la OMS en Tuberculosis. Noveno informe. Ginebra: Organización Mundial de La Salud. Disponível em: http://www.bvs.ins. gob.pe/print/oms/informes_tecnicos/552.pdf. Acesso em: 8 out. 2016. 1974.

PITTELLA, José Eymard Homem.

Construindo o saber da ciência. Belo Horizonte: Coopmed. 2012.

PITTELLA, José Eymard Homem. O processo de avaliação em ciência e a indicação de Carlos Chagas ao prêmio Nobel de Fisiologia ou Medicina. Revista da Sociedade Brasileira de Medicina Tropical, v.42, n.1, p.67-72. 2009.

PRATA, Aluízio.

Comemoração do centenário da descoberta do Schistosoma mansoni no Brasil. Revista da Sociedade Brasileira de Medicina Tropical, v.41, n.6, p.689-691. 2008.

SILVA, André Felipe Cândido da.

A Brazilian in the Reich of Wilhelm II: Henrique da Rocha Lima, Brazil-Germany relations and the Instituto Oswaldo Cruz, 1901-1909. História, Ciências, Saúde-Manguinhos, v.20, n.1, p.93-117. Disponível em: http://www.scielo. br/scielo.php?script=sci_arttext\&pid $=$ S0104 $59702013000100006 \& \operatorname{lng}=$ en $\&$ nrm =iso \& tlng= en. Acesso em: 15 dez. 2016. 2013.

SOUZA ARAUJO, Heráclides César de. Antônio Cardoso Fontes: 1879-1943. Memórias do Instituto Oswaldo Cruz, v.39, n.2, p.I-IX. 1943.

VIEIRA, Cássio Leite; VIDEIRA, Antônio Augusto Passos.

Carried by history: Cesar Lattes, nuclear emulsions, and the discovery of the pi-meson. Physics in Perspective, v.16, n.1, p.3-36. 2014.

ZUCKERMAN, Harriet. Scientific elite: nobel laureates in the United States. New York: Free Press. 1977.

\section{$\rightarrow \rightarrow \rightarrow<<$}

